\title{
OUVIDORES DE VOZES DE UM SERVIÇO DE SAÚDE MENTAL: CARACTERÍSTICAS DAS VOZES E ESTRATÉGIAS DE ENFRENTAMENTO
}

\author{
LOS QUE OYEN VOCES EN UN SERVICIO DE SALUD MENTAL: \\ CARACTERÍSTICAS DE LAS VOCES Y ESTRATEGIAS \\ DE ENFRENTAMIENTO
}

VOICE HEARERS OF A MENTAL HEALTH SERVICE: VOICE CHARACTERISTICS AND COPING STRATEGIES

\author{
Maria Laura de Oliveira Couto ${ }^{1}$ e Luciane Prado Kantorski ${ }^{1}$ \\ ${ }^{1}$ Universidade Federal de Pelotas, Pelotas/RS, Brasil
}

\begin{abstract}
RESUMO: Objetivou-se compreender a experiência de ouvir vozes a partir das características e conteúdos das vozes, e das estratégias utilizadas por dezesseis ouvidores usuários de um Centro de Atenção Psicossocial do Sul do Brasil. Trata-se de uma pesquisa qualitativa de caráter exploratório. Se deu através de entrevistas semiestruturadas e análise de conteúdo. Evidenciou-se que as características e conteúdos das vozes podem ser determinantes das reações emocionais dos ouvidores frente à experiência, sendo mais difícil lidar com ela quando os conteúdos são negativos. Através das estratégias utilizadas pelos ouvidores, percebeu-se uma resistência ao modelo biomédico, mesmo dentro de um serviço de saúde mental. Conclui-se que há uma necessidade de se pensar outras possibilidades de recuperação para as pessoas que ouvem vozes, que deem conta da complexidade da experiência e que sejam condizentes com o modelo de atenção psicossocial.
\end{abstract}

PALAVRAS-CHAVE: Saúde mental; Esquizofrenia; Desinstitucionalização.

RESUMEN: El estudio objetivó comprender la experiencia de oír voces a partir de las características y contenidos de las voces y las estrategias utilizadas por dieciséis oyentes que utilizan un Centro de Atención Psicosocial en el sur de Brasil. Esta es una investigación exploratoria cualitativa. Se llevó a cabo mediante entrevistas semiestructuradas y análisis de contenido. Se destacó que características y contenidos de las voces pueden ser determinantes de reacciones emocionales de los oidores delante la experiencia, siendo más difícil ocuparse de ella cuando los contenidos son negativos. A través de estrategias utilizadas por los oidores, se notó una resistencia al modelo biomédico, aunque dentro de un servicio de salud mental. Se concluye que hay una necesidad de pensar otras posibilidades de recuperación para las personas que oyen voces, que aporten la complejidad de la experiencia y que sean compatibles con el modelo de atención psicosocial. PALABRAS CLAVE: Salud mental; Esquizofrenia; Desinstitucionalización.

ABSTRACT: The study aimed to understand the experience of hearing voices from the analysis of the characteristics and contents of the voices, and of the strategies used by sixteen voice hearers who use a Psychosocial Care Center in Southern Brazil. This is a qualitative exploratory research, conducted through semi-structured interviews and content analysis. It was evidenced that the characteristics and contents of the voices can be determinant of the hearer's emotional reactions to the experience, being more difficult to deal with when those are negative. By analyzing the strategies used by the hearers, resistance to the biomedical model was perceived even within a mental health service. It was concluded that there is a need to think about other possibilities of recovery for people who hear voices, possibilities that take into account the complexity of the experience and that are consistent with the psychosocial care model. KEYWORDS: Mental health; Schizophrenia; Deinstitutionalization. 


\section{Introdução}

Com o surgimento do Movimento Internacional de Ouvidores de Vozes, na Holanda, em 1987, ouvir vozes que os outros não ouvem passa a ser considerada uma experiência humana que, por si só, não pode ser entendida como sintoma de transtornos mentais (Baker, 2016). Além disso, várias pesquisas apresentam que entre 4\% e $8 \%$ da população geral ouvem vozes, e a maioria não possui diagnóstico psiquiátrico e nem precisa de ajuda profissional (Eaton, Romanoski, Anthony, \& Nestadt,1991; Johns \&Van Os, 2001; Sommer et al., 2010, Tien, 1991 ), o que evidencia a abrangência do tema.

Assim, apesar de o conteúdo e as características das vozes terem sido negligenciados por muito tempo, eles vem ganhando maior atenção no meio científico e clínico, visto que são crescentes as evidências de que a compreensão dessas variáveis é crucial para delimitar a forma de trabalhar com a experiência de ouvir vozes (Romme \& Escher, 2000), pois trata-se de um fenômeno complexo, que não envolve apenas a audição de vozes em si, mas também diversos tipos de sons que os outros não conseguem ouvir.

Dessa forma, o Movimento Internacional de Ouvidores de Vozes tem proporcionado alternativas para os ouvidores que não se sentem contemplados pelas abordagens propostas pela psiquiatria (Corstens et al., 2014), visto que já se tem conhecimento de que a medicação é eficaz para alguns sujeitos, mas que ainda existe uma proporção de $30 \%$ que ouve vozes mesmo utilizando doses elevadas da mesma (Curson et al., 1985).

Assim, um dos princípios do Movimento Internacional de Ouvidores de Vozes é que a aceitação das vozes e a elaboração de estratégias para conviver com as mesmas costuma ser mais eficaz do que tentar eliminá-las, propondo que a crença de que o ouvidor poderá obter sucesso ao lidar com as vozes permitirá manter-se saudável e livre do sofrimento psíquico que a experiência costuma causar (Corstens et al., 2014).

Portanto, fica clara a necessidade de se pensar a audição de vozes para além do viés psiquiátrico, de se investigar suas características e conteúdos de forma a auxiliar o ouvidor no processo de autoconhecimento, e assim viabilizar a utilização de estratégias diárias para lidar com essa experiência. Frente a isso, o presente estudo objetivou compreender a experiência de ouvir vozes a partir das características e conteúdos das vozes, e das estratégias utilizadas por ouvidores usuários de um serviço de saúde mental.

\section{Metodologia}

O estudo possui abordagem qualitativa do tipo descritiva e foi realizado em um CAPS tipo II, do Sul do Brasil. Foi escolhido este serviço por ele ter criado o primeiro grupo de ouvidores da região.

Os participantes do estudo foram dezesseis ouvidores de vozes que frequentam o serviço e que participam do grupo sobre essa experiência. Em relação às características dos participantes, 11 são mulheres e 5 são homens, com idade entre 26 e 57 anos e com crenças heterogêneas no que se refere à religião: 1 umbandista, 3 espíritas, 2 relataram acreditar em Deus e 10 disseram não possuir religião. Para a seleção dos participantes foram considerados os seguintes critérios de inclusão: adultos, com idade igual ou maior a 18 anos, que frequentam o CAPS II e o grupo de ouvidores de vozes; estar de acordo com o Termo 
de Consentimento Livre e Esclarecido (TCLE); e concordar com a divulgação e publicação dos dados em meio acadêmico e científico. Enquanto que, como critério de exclusão, considerou-se apenas o fato de o ouvidor não permitir o uso de gravador nas entrevistas.

A coleta de dados se deu por meio de entrevistas semi-estruturadas, as quais tiveram, em média, duração de 30 minutos, sendo realizada em abril de 2018. Foi utilizado gravador de voz para registrar as entrevistas, as quais foram transcritas na íntegra.

As entrevistas abordaram a experiência de ouvir vozes, quando começou, quais as características das vozes, se o ouvidor consegue conversar com elas, se recebe ordens das mesmas, e quais estratégias utiliza par lidar com a experiência. Os dados foram analisados por meio da análise de conteúdo de Bardin (2011). Portanto, inicialmente foi realizada a pré-análise das entrevistas, na qual foram produzidas as primeiras impressões acerca do conteúdo dos documentos. Em seguida, foi realizada a exploração do material, na qual o olhar para o mesmo é direcionado com base no referencial teórico escolhido e nos objetivos da pesquisa, a fim de determinar as categorias de análise. A última etapa foi a de tratamento dos resultados, na qual é realizada uma reflexão acerca das categorias constituídas, no intuito de possibilitar uma interlocução entre as discussões apresentadas na proposta de pesquisa e os discursos dos sujeitos materializados nas entrevistas (Bardin, 2011).

Os participantes foram identificados ao longo do texto como "entrevistado 1, entrevistado 2" e assim por diante. O estudo foi aprovado no Comitê de Ética em Pesquisa da Faculdade Enfermagem da Universidade Federal de Pelotas, sob o parecer n. 2.201.138, e seguiu os preceitos éticos postulados no Código de Ética dos profissionais de Psicologia, bem como a Resolução n. 466/2012 do Ministério da Saúde (MS) e do Conselho Nacional da Saúde (CNS), que estabelece as diretrizes e normas regulamentadoras de pesquisas envolvendo seres humanos.

\section{Resultados e discussão}

Os conteúdos das entrevistas realizadas com os ouvidores de vozes foram organizados em duas categorias: características e conteúdo das vozes; e estratégias para lidar com as vozes. As categorias estão relacionadas com os objetivos da pesquisa, e os conteúdos trabalhados em cada uma delas foram selecionados com base na repetição dos mesmos na fala dos entrevistados. Assim, os conteúdos acerca das caracteristicas das vozes, bem como das estratégias para lidar com as mesmas, que apareceram mais vezes ao longo das entrevistas, foram considerados os mais relevantes para serem apresentados e discutidos.

\section{Características e conteúdo das vozes}

Nesta categoria, serão trabalhados os conteúdos que se referem às características das vozes, ou seja, se elas são depreciativas, de comando, de chamado, premonitórias, ou apenas ruídos, por exemplo. Assim como os conteúdos das mesmas, ou seja, se elas ordenam que a pessoa faça mal a si ou aos outros, se elas preveem acontecimentos referentes à morte de pessoas ou se preveem coisas positivas, entre outros.

O fato de o conteúdo das vozes vir ganhando espaço nas discussões da área da saúde mental denuncia uma série de condições de possibilidade que permitem que esse discurso 
acerca das vozes seja legitimado em determinado período e sociedade. Isso se dá, segundo Henning (2008), porque a forma como as pessoas pensam e organizam seus discursos, os quais são considerados verdadeiros em uma determinada sociedade, é determinado pela episteme em vigor em determinado tempo histórico. Esta episteme dá condições de possibilidade para a produção de verdades, saberes, formas de entender o mundo e se relacionar socialmente no que se refere aos aspectos éticos e políticos.

Isso explica porque a compreensão da audição de vozes enquanto experiência, que demanda atenção aos seus conteúdos e características, é legitimada neste momento histórico e social e não em outro. Nesse sentido, pode-se pensar que uma das condições de possibilidade para que as discussões em torno da experiência de ouvir vozes tomassem outros caminhos no Brasil foi a própria reforma psiquiátrica, pelo fato de ter sido o início de uma visão humanizada do tratamento em saúde mental, que rompe com o modelo manicomial e propõe o cuidado em liberdade (Pires, Ximenes, \& Nepomuceno, 2013).

Essa nova perspectiva de cuidado tornou possível questionar, por exemplo, a soberania do saber médico em relação às outras áreas de conhecimento, a própria concepção de clínica, e o papel da medicação na vida dos sujeitos. O Movimento Internacional de Ouvidores de Vozes, apesar de já contar com 32 anos de existência, chegou tardiamente no Brasil, até mesmo porque a Reforma Psiquiátrica só aconteceu em 2001 no país (Lei n. 10216, 2001), e antes disso não havia espaço para tais questionamentos, muito menos para se propor que a medicação fosse apenas uma das formas possíveis de tratamento, e não a única, como faz o Movimento (Romme \& Escher, 2000). Desde então, até mesmo um estudo anterior ao movimento, considerado pioneiro, vem sendo amplamente citado em diferentes pesquisas, pois já trabalhava, em 1894, com audição de vozes em uma amostra de dezessete mil pessoas (Sidgwick, 1894).

Atualmente, entre os estudos que vem investigando as características e os conteúdos das vozes, está o de Beavan e Read (2010), que ao realizar entrevistas semiestruturadas com 50 ouvidores, conseguiram definir quantos ouviam vozes positivas, quantos ouviam vozes negativas e quantos ouviam vozes neutras ou ambíguas. Como resultado, eles obtiveram que a maioria ( $92 \%$ ) ouvia vozes neutras ou ambíguas, as quais abarcavam vozes que comentavam, como as dos entrevistados 7 e 14; que chamavam pelo ouvidor, como as do entrevistado 13; e sons diversos, como no caso dos entrevistados 11 e 15 .

Todos os vizinhos sabem um pouco o que eu ouço, o que eu falo... Sabe, parece que todo mundo sabe um pouquinho. Meus parentes, todo mundo... Ou do que eu participo às vezes... eles fazem como dizem as minhas tias, eles comentam que eu não faço nada, é como se dissesse o contrário. (Entrevistado 7)

Eu escuto... eu posso dizer que eu escuto frequentemente. Frequentemente eu escuto mais ruídos, eu já tô acostumada a escutar na minha casa, por exemplo, agora eu moro sozinha, o quarto do meu filho fica vazio, eu moro num chalé pré-fabricado e a minha casa é com assoalho, então eu escuto direitinho uma pessoa que levanta da cama e que caminha no assoalho, vai até a cozinha. Isso me dá mais medo, mas eu escuto uma pessoa que se esfrega na parede também, não me dá mais medo porque eu já sei do que se trata. (Entrevistado 11)

Eu ouvia alguém gritar e eu abria a porta e não era ninguém, eu ia olhar e não era ninguém. Não dava medo por que eu ia lá vê. (Entrevistado 13) 
Essas [vozes] eu acho amedrontadoras, porque são as coisas assim de deboche, de rir... parece que eles tão zombando de mim sabe? Esse ai me dá medo. (Entrevistada 14)

Sim. Eu ouvia a voz. Vinha de um rádio. Falando, tocando a música. (Entrevistado 15)

Há também as vozes de premonição, como as do entrevistado 6, que segundo Faccio et al. (2013), é comum levarem o ouvidor a crer que possui algum tipo de poder, como clarividência, e que isso pode levar a um aumento de ansiedade, mas pode também servir como estímulo para enfrentar as vozes.

A maneira de escutar era muito estranha, porque era como se me falassem o que ia acontecer com as pessoas... Eu, antes da minha mãe falecer... é... essa eu não contei para ela, porque elas me disseram que ela ia morrer. Não adiantava, que ela ia morrer. (Entrevistado 6)

Ouvir vozes, portanto, tende a ser uma experiência intensa, intrusiva, e que pode envolver todos os sentidos, e não apenas a audição (Couto \& Kantorski (2018), como nos casos dos entrevistados 1, 2 e 5 a seguir. Da mesma forma, análises estatísticas das características das vozes mostraram que o conteúdo das mesmas é um preditor muito significativo das reações emocionais do ouvidor frente à experiência de ouvir vozes (Beavan \& Read, 2010). Nos casos dos entrevistados 1, 2 e 5, as vozes possuíam características negativas, eram agressivas e traziam forte conteúdo de morte, fazendo com que estes ouvidores apresentassem suas experiências de audição de vozes como eventos traumáticos.

E eu ouvia, as vezes assim né, vozes, uma pessoa me chamar... Às vezes uma pessoa me tocava né ... Aí tem épocas mesmo que eu fico ruim, aí começa a ver vulto, começa ver coisa... de me matar, e tem que matar um e aquela coisa toda né... (Entrevistado 1)

Todos os dias. Todos os dias eu ouvia as vozes, fora os vultos né. Eu via vultos também... Passava os vultos na minha frente e automaticamente as vozes vinham no meu ouvido "mata ele! Mata ele! Mata ele!" “te mata! Te mata!"... Me comandavam. (Entrevistado 2)

E essas vozes elas me incomodam muito, muito porque é assim ó, eu tô dormindo e aquelas crianças tão tudo na minha volta me chamando, e eu quero pegar elas, abraçar elas, e tem um homem com uma capa preta assim grande e uma espada enorme... ele bota aqui bem em cima da minha cabeça e ele diz que se eu pegar uma daquelas crianças ele me mata... vejo, sabe, elas todas furadas todas assim ensanguentadas e aquilo me deixa nervosa sabe, muito, elas não tem os dedinhos. (Entrevistado 5)

Esse fato pode estar relacionado com a história de vida de cada ouvidor, visto que ela está diretamente relacionada com o conteúdo das vozes e pode conter dados de eventos traumáticos que o expliquem (Andrew, Gray, \& Snowden, 2008; Romme \& Escher, 2000). No caso do entrevistado 2 , as vozes surgiram em meio a uma desilusão amorosa muito forte, e ordenavam que ele matasse sua companheira na época. De forma semelhante, a entrevistada 5 começou a ouvir vozes quando precisou retirar o útero, situação que foi muito 
traumática, visto que ela queria ter mais filhos. Passou então a ver crianças mutiladas que ela não conseguia alcançar, pois um homem de capa preta a impedia. E a entrevistada 16, que já ouvia vozes de conteúdo positivo, e com a morte do irmão isso mudou.

Ela mandava eu me arrumar, eu fazia maquiagem, coisa assim pra sair, ai depois que o meu irmão morreu, aí não. Aí agora é só esse vulto preto que passa por mim e fica falando nos meus ouvidos e me chamando, fazendo de boba. (Entrevistada 16)

Nas falas dos entrevistados 1 e 2 , já é possível verificar vozes de comando, as quais tendem a ser as mais intrusivas e prejudiciais a vida diária do ouvidor, contudo, nas falas dos entrevistados a seguir $(3,8,9,10,12)$ fica mais evidente a influência das mesmas na vida dos entrevistados.

Não, ela falava coisas pra mim tipo "eu vou matar a tua mãe", "eu vou estrangular tua mãe", "tu vai chegar em casa a tua mãe não vai ta mais lá”, eu ficava sufocada, quando eu chegava em casa e via que a minha mãe tava bem, tava lá, eu me aliviava... Agora ela me diz tipo "te corta", "te mata"... "Te estrangula", "te enforca." (Entrevistada 3)

Elas só mandavam eu ir embora. Agora só vejo vulto. (Entrevistado 8)

Elas mandam eu me matar... um pouco passa e depois volta de novo, passa um pouquinho e volta de novo. É todo dia. (Entrevistado 9)

Dizem que eu sou inútil, que eu não presto, e por aí vai... outros nomes pejorativos. ...Ele fala normal comigo, "te machuca aqui, corta ali que vai passar a dor" "te machuca porque assim vai doer menos"... e assim vai. (Entrevistado 10)

Eu gosto que chegue o dia de uma vez, por que de noite eu vejo muita coisa... O pai eu não levei nada e ele anda pedindo pra mim, que é pra mim ir lá. Eu não levei nada nada nada, ele morreu em junho, a mãe foi em 2000... ele foi em junho há muito tempo já. (Entrevistado 12)

A partir do exposto, vozes de comando podem ser muito angustiantes e prejudiciais ao ouvidor, como mostram os entrevistados 3, 9, 10 e 12. Por esse motivo, faz-se necessário procurar estabelecer possíveis fatores associados ao fato de a pessoa resistir ou não ao comando das vozes, o que foi amplamente discutido por Mackinnon et al. (2004). Em seu estudo, os autores encontraram que, em sua amostra de pesquisa, os que ouviam vozes de comando descreveram-nas como mais negativas do que os que não ouviam vozes de comando, e mostraram-se muito preocupados e amedrontados pelas mesmas. Ademais, os que não conseguiam resistir aos comandos, ouviam vozes mais negativas, apresentavam mais sintomas negativos e faziam uso de doses mais elevadas de medicação.

Um dos aspectos mais preocupantes das vozes de comando é que elas normalmente pedem que o ouvidor faça mal a ele ou a outros, como ferir ou matar, como é possível constatar nos relatos de sete ouvidores que compuseram a amostra do presente estudo $(1,2,3,8,9,10,12)$.

Nessa perspectiva, Connor e Birchwood (2011) procuraram estabelecer o impacto da percepção do ouvidor acerca das emoções expressas pelas vozes no pensamento suicida, 
em uma amostra de 102 ouvidores que faziam uso de serviço de saúde mental, assim como os do presente estudo. Os achados mostraram que quanto maior o poder que o ouvidor atribui às vozes, e mais perceptível a emoção expressa pelas vozes, maiores os riscos de depressão e ideação suicida.

As vozes de comando tendem a causar no ouvidor uma crença de que ele é responsável por evitar danos, o que pode se tornar um estressor a mais em meio a sua experiência de ouvir vozes, visto que quanto mais responsável ele se sente por evitar danos, mais estressante se torna o fato de ouvir vozes de comando (Ellet et al., 2017).

Esse dado evidencia, entre outras coisas, a importância de se trabalhar com o ouvidor a diferenciação entre ele e a voz, ou seja, trabalhar o fato de que as vontades de ambos não precisam ser as mesmas, que ele pode ter um poder maior sobre a voz e que é ele quem decide seus atos. Esse é o caso do entrevistado 2, que por não conseguir resistir aos comandos das vozes, acabou agredindo a sua mãe. Esse fato levou-o a sair de casa, devido à insegurança dos familiares frente a sua presença.

No caso dos entrevistados 3, 8, 9, 10 e 12, fica evidente certo distanciamento entre eles e as suas vozes. Segundo Vaughan e Fowler (2004), o fato de a voz se manifestar de forma dominante, associado à falta de comunicação ou uma comunicação empobrecida entre o ouvidor e a voz, está fortemente associado a elevados níveis de angústia e estresse. Porém, apesar de muitos ouvidores apresentarem dificuldade em estabelecer relações mais positivas e menos dominantes com as suas vozes, existem casos em que estes se encontram satisfeitos com as suas experiências, como é o caso do entrevistado 4, exposto a seguir.

Normalmente é como eu falei pra C.A., é uma voz... uma voz que parece que ajuda, parece que me protege assim das pessoas... não é uma voz que manda eu cortar o pulso ...não, é uma voz boa, é uma voz boa.” (Entrevistado 4)

Ao longo de suas pesquisas, Romme e Escher (2000) se depararam com um elevado número de ouvidores de vozes que nunca se tornaram pacientes psiquiátricos, pois nunca necessitaram de ajuda para lidar com as vozes, bem como acreditavam que elas ajudavam-nos no dia-a-dia. No curso de seus trabalhos, uma de suas conclusões foi que a presença das vozes não seria o verdadeiro problema, mas a inabilidade para lidar com as mesmas (Romme \& Escher, 2000).

Assim, segundo Baker (2016), as vozes podem ter um impacto positivo na vida do ouvidor, quando este as percebe como fonte de reconhecimento, ao invés de dominantes e intrusivas. Nesse sentido, muitas pesquisas vem sendo realizadas no intuito de descrever as diferenças entre populações de ouvidores que fazem uso de algum serviço de saúde mental e os que não o fazem. A maioria dessas pesquisas vem mostrando que a diferença entre essas populações está, precisamente, no conteúdo das vozes e suas características, ou seja, se são intrusivas ou dominantes e dão comandos, como relatado pela maioria dos entrevistados deste estudo, ou se são gentis e amigáveis, como apresentado pelo entrevistado 4 (Mackinnon et al., 2004; Léon-Palacios et al., 2015; Varese et al., 2016).

Como exposto, os ouvidores de vozes entrevistados nesta pesquisa possuíam, majoritariamente, experiências negativas com as vozes. Esse fato está de acordo com o resultado das pesquisas populacionais, que constataram que usuários de serviços de saúde mental ouvem mais vozes negativas do que os não usuários. Esse é precisamente o motivo que os leva a procurar ajuda. As únicas exceções nesta pesquisa foram os entrevistados 4, 
que apesar de conviver harmoniosamente com as vozes, já apresentou dificuldade em lidar com as mesmas no passado, o que fez com que procurasse ajuda no serviço, onde faz acompanhamento até hoje, e a entrevistada 16, que, apesar de ouvir vozes negativas com muita frequência, relata que há dias em que só ouve vozes positivas.

Outro aspecto que merece atenção é o de que dos 16 entrevistados, 11 são mulheres. Esse fato também vai ao encontro de dados populacionais que mostram uma prevalência de audição de vozes em mulheres (Sidgwick, 1894; Sharma, et al., 1999; Shevlin, et al., 2007). No estudo de Sidgwick (1894) foi evidenciado, em uma amostra de 17.000 pessoas, uma prevalência de $12 \%$ de audição de vozes em mulheres em relação a 7,8\% em homens. De forma semelhante, no estudo de Sharma et al. (1999), obteve-se uma proporção significativamente maior de pacientes do sexo feminino (30/45) do que os pacientes do sexo masculino (36/77) com experiência de ouvir vozes. Assim como no estudo de Shevlin et al. (2007), em que encontrou-se uma prevalência de 59\% de audição de vozes em mulheres, em uma amostra de 5.893 participantes.

Essa prevalência, além de informar sobre diferenças de nível orgânico entre homens e mulheres, instiga reflexões acerca do papel social da mulher, principalmente quando as vozes trazem conteúdos negativos, que diminuem a autoestima e deslegitimam sua existência. Esse é o exemplo da entrevistada 16, que sente-se culpada por não conseguir cuidar da casa e não poder ter filhos.

Aí a voz diz "que importa? Isso ai já acabou. Essa historinha, tu só ta brincando de casinha. Tu não cresceu" "tu é boba, tu não cresceu, tu ainda é criança, tem a cabeça de criança... por isso tu nem prestou pra ter filho” Sabe? Fica puxando essas coisas brabas do passado. (Entrevistada 16)

Esse conteúdo mostra que, talvez, ainda hoje, o inconsciente das mulheres brasileiras esteja atrelado às ideias passadas por gerações, aonde a mulher devia cuidar da casa, do esposo e dos filhos, ser recatada e decente, "sendo a fecundidade indispensável ao casamento, a esterilidade levada ao repúdio, e o adultério implicava o abandono ou até a morte da mulher" (Silva et al., 2005, p.73).

A partir do exposto, fica nítida a importância de não minimizar o significado do conteúdo das vozes e suas características, e passar a explorar em profundidade seus possíveis sentidos e relações com a história de vida do ouvidor e com o seu contexto histórico e social, visto que isso vem se mostrando crucial para a compreensão e redução da angústia e estresse de muitos ouvidores de vozes. No quadro 1, é possível visualizar as principais características das vozes de cada ouvidor. 


\section{Quadro 1 - Características das vozes dos entrevistados}

\begin{tabular}{|c|c|}
\hline Entrevistado & Característica das vozes \\
\hline 1 & Vozes de chamado e de comando \\
\hline 2 & Vozes de comando \\
\hline 3 & Vozes de ameaça e de comando \\
\hline 4 & Vozes que comentam \\
\hline 5 & Vozes de chamado e de ameaça \\
\hline 6 & Vozes premonitórias \\
\hline 7 & Vozes depreciativas \\
\hline 8 & Vozes de comando \\
\hline 9 & Vozes de comando \\
\hline 10 & Vozes depreciativas e de comando \\
\hline 11 & Ruídos \\
\hline 12 & Vozes de comando \\
\hline 13 & Vozes de chamado \\
\hline 15 & Vozes de chamado e de deboche \\
\hline 16 & Vozes de pessoas e som de rádio \\
\hline 14 & Vozes de comando, de chamado e depreciativas \\
\hline
\end{tabular}

Fonte: dados do trabalho de campo da pesquisa, 2018.

\section{Estratégias para lidar com as vozes}

Nesta categoria serão trabalhadas as estratégias utilizadas pelos ouvidores de vozes para lidar com essa experiência, como, por exemplo, estabelecer um diálogo com as vozes, questionar o que elas dizem, se envolver em outras atividades como forma de distração, ou até mesmo ignorá-las.

As entrevistas com os ouvidores de vozes mostraram que as estratégias para lidar com as mesmas surgem de um processo individual, que se constrói a partir de suas histórias de vida, de suas realidades culturais e das diferentes condições de apoio familiar e social que cada um possui.

Assim, diferentes tipos de estratégias foram evidenciadas, algumas mais adaptativas, que denunciavam uma resistência comportamental ao modelo biomédico, tais como: buscar estabelecer um diálogo com as vozes; enfrentar as vozes; e conversar com outras pessoas sobre o assunto. E outras menos adaptativas, como: buscar distrações para não ouvir as vozes; ignorar o que as vozes dizem; e tentar acabar com o sofrimento causado pelas vozes cometendo suicídio.

Contudo, o fato de alguns ouvidores apresentarem maior dificuldade em lidar com a experiência de ouvir vozes, não significa que há uma ausência completa de resistência ao modelo biomédico por parte dos mesmos, visto que, para Armstrong e Murphy (2015), há dois tipos de resistência: a comportamental e a conceitual. Portanto, mesmo que esses sujeitos ainda não consigam enfrentar as vozes e dialogar com elas em busca de uma relação mais positiva com a experiência, eles podem, ao mesmo tempo, não gostar da ideia 
de depositar todas as suas expectativas de recuperação em um tratamento medicamentoso, assim como podem ter consciência dos efeitos colaterais dos medicamentos, ou seja, podem resistir apenas conceitualmente ao modelo biomédico. Esse fato vai ao encontro da afirmação de Grabois (2011), de que para Foucault, “jamais somos aprisionados pelo poder, sendo sempre possível modificar a dominação que a relação de poder tenta exercer em condições determinadas e segundo uma estratégia precisa” (p. 12).

Assim, os ouvidores entrevistados se mostraram em diferentes fases de enfrentamento das vozes, o que, segundo Romme e Escher (1997), pode ser dividido em três momentos: fase de surpresa; fase de organização; e fase de estabilização. A primeira se refere ao início da experiência de ouvir vozes, que habitualmente é súbito e assustador. Na fase de organização, dá-se um processo de seleção e de comunicação com as vozes, enquanto que na de estabilização, é quando se desenvolvem estratégias mais profícuas e contínuas de lidar com as mesmas (Romme \& Escher, 1997).

Nas falas a seguir, podem ser evidenciados momentos de grande sofrimento psíquico, que levaram os sujeitos a cogitar tirar a própria vida para acabar com as vozes:

Eu queria me livrar delas [das vozes], aí eu passei numa farmácia e comprei uma caixa de Lexotan. Tomei toda aquela caixa de Lexotan. Aí o que é que aconteceu... eu cheguei em casa e a filha da N. me ajudou. Chamou o SAMU, chamou o marido dela e me levaram para o sanatório de novo. (Entrevistado 2)

Ai eu digo "não, eu já tomei os meus remédio hoje, tenho certeza que eu já tomei” ai ele [a voz] fica mau, ele fica muito mau... Ai a gente pensa qualquer coisa né, começo a pensar a botar meu plano em prática... De se matar. (Entrevistada 16)

Segundo Romme e Escher (1997), as pessoas que não se entendem com as vozes costumam sentir-se mais fracos do que elas, experimentam mais vozes negativas e de comandos, não conseguem estabelecer limites para as mesmas, utilizam mais estratégias de distração, sentem-se menos apoiados pelo meio social e acabam comunicando menos sobre as suas experiências auditivas. As falas apresentadas refletem essa realidade, nas quais os entrevistados conseguem expor a magnitude do sofrimento causado pelas vozes e a dificuldade em estabelecer estratégias mais adaptativas para lidar com as mesmas. De forma semelhante, porém menos desadaptativa, os autores das falas a seguir relataram procurar distrair-se do conteúdo das vozes, realizando outras atividades ou apenas ignorando-as, como estratégias diárias para lidar com elas.

Eu tento conversar muito com a minha mãe assim... às vezes eu vou e converso, às vezes eu jogo vídeo game um pouco, ou... mas é brabo assim, tá meio difícil de eu lidar. (Entrevistado 3)

Por isso, eu não falo com elas. É por isso que eu acho que eu tenho esse controle delas, porque eu não falo com elas. (Entrevistado 4)

E ficar assim, num quarto escuro bem quietinha, porque as vozes vem me incomodar, e aí eu me abafo assim com o travesseiro pra elas não me incomodar, eu boto bastante algodão... e fico bem quietinha, mas elas vem e ultrapassam o algodão e o travesseiro. (Entrevistado 5)

Eu fico quieta. Agora é brabo, eu não sei... Eu ligo o rádio. (Entrevistado 12) 
No estudo de De Jager et al. (2016), foram analisadas as narrativas de 11 ouvidores a respeito da experiência de ouvir vozes, e encontrou-se dois tipos de recuperação: voltando para/empoderamento e desativando/hibernação protetora. Nos casos de hibernação protetora, assim como apresentado nas falas dos entrevistados 3, 4, 5, e 12, os ouvidores mostraram aproveitar todos os recursos disponíveis para fazer cessar a audição das vozes, mesmo que isso os tomasse muita energia. Assim, mesmo que esses entrevistados ainda não fossem capazes de enfrentar as vozes, eles já se mostravam com estratégias mais adaptativas do que se machucar, se cortar, ou acabar com a própria vida, como nos casos dos entrevistados 2 e 16.

Segundo Romme e Escher (2000), duas estratégias que podem começar a ser utilizadas em curto prazo são: checar se o que as vozes dizem é verdade; e conversar com alguém sobre elas, como pode ser observado nas falas a seguir, respectivamente:

Eu fui olhar três vezes, me levantei e fui olhar, aí depois que fiquei com medo e já não saí mais do quarto... É. Eu enfrento, eu vou lá ver, mas eu fico já na retaguarda. (Entrevistado 14)

Antes eu falava para minha mãe, porque eu tinha só ela né... mas agora, se eu escutar, eu não falo. Só agora, para a Doutora S., que eu tô falando... para ela né... Aí eu me acostumo. Porque antes eu nem falava com ninguém sobre as vozes, nada, eu não falava no grupo mesmo, eu nunca conversava. (Entrevistado 6)

Segundo Romme e Escher (2000), também seria interessante conversar sobre as vozes com outros ouvidores, pois saber que outras pessoas também ouvem e partilham de experiências parecidas traria um sentimento de alívio e reconhecimento. Contudo, o simples fato de conversar sobre a temática torna mais fácil superar os sentimentos de vergonha e ansiedade causados pela audição de vozes.

Segundo Place et al. (2011), falar sobre a própria história faz com que a pessoa ocupe um lugar em sua narrativa, assim como proporciona um retorno ao conteúdo das vozes, possibilitando novos insights e a atribuição de novos sentidos. Como citado anteriormente, os ouvidores entrevistados mostraram estar em diferentes fases de enfrentamento, assim, as falas a seguir apresentam situações em que eles sentiam-se mais encorajados a estabelecer um diálogo com as mesmas.

Mas assim, como eu te disse, se tem uma voz eu escuto a mensagem sabe, que aí eu fico "mas por que disso? Por quê?" e discuto". (Entrevistado 1)

Eu tento [conversar com as vozes], mas às vezes parece que eles estão de bronca comigo, não querem saber... Às vezes eu nem quero saber de responder, simplesmente deixo passar". (Entrevistado 7)

Tentei semana passada e ela [a voz] disse assim "não quero ser teu amigo. (Entrevistado 9)

A té eu perguntei quando tava andando de bicicletinha a motor "tá aí fala comigo, quem é? Se é um rádio, se é uma música, quem é” eu não conseguia definir por causa do barulho e acelerei mais ainda e "fala comigo, fala comigo, quem é? Quem é?” e ninguém falava nada. (Entrevistado 15) 
No estudo de Petrus et al. (2012), verificou-se que "manipular e regular as vozes" foi uma das estratégias mais utilizadas pela população chinesa de Hong Kong. Mesmo que levassem anos para conseguir dialogar com as vozes, muitos ouvidores conseguiam entrar em contato com elas quando as ouviam seletivamente. Nas falas dos entrevistados 1, 7, 9 e 15, são evidentes as tentativas de obter uma resposta das vozes, o que se torna possível quando o medo causado pela experiência diminui.

De acordo com Kantorski et al. (2017), o medo é proveniente de uma construção social, a qual relaciona a audição de vozes à loucura e à esquizofrenia, tornando essa experiência algo indesejável e estigmatizante. Somado a isso, o medo também pode estar relacionado com a possibilidade de aumento de dose de medicação, uma nova hospitalização e o afastamento dos membros da família (Contini, 2017).

No caso dos participantes desta pesquisa, a questão da medicação é muito presente, visto que todos utilizam e fazem acompanhamento com o psiquiatra do serviço. Assim, o medo do aumento da dose, que acarretaria mais efeitos colaterais, acaba por ser um estressor adicional na vida desses sujeitos. Esse medo também denuncia os focos de resistência ao modelo biomédico, e o desejo de encontrar outras possibilidades de recuperação, que valorizem o diálogo, a narrativa, e o sentido que cada ouvidor atribui às suas vozes.

Nessa perspectiva, Foucault (2001) defende que "a resistência vem então em primeiro lugar, ela permanece superior a todas as forças do processo, ela obriga as relações de poder a mudar" (p. 1559). Assim, nesse caso, quando os ouvidores deixam de relatar aos profissionais que estão ouvindo vozes com mais frequência, ou que estas estão dando comandos de agressão, pelo medo das consequências que essa informação possa acarretar, eles estão reivindicando mudanças nessa relação de poder com o serviço. Assim, percebe-se que mesmo que o modelo de atenção psicossocial seja um grande avanço no que se refere às práticas de cuidado e compreensão do ser humano como um todo, configurando-se como uma forma de resistência ao modelo manicomial, ele ainda opera de acordo com o modelo biomédico no que se refere ao uso da medicação, que ao invés de ser vista como uma das possibilidades de tratamento, como prevê a atual política de saúde mental, ela é entendida como a principal, ou a única possibilidade de tratamento efetivo (Yasui \& Costa-Rosa, 2008).

Dessa forma, fica evidente que mesmo com as mudanças na política de saúde mental, ainda prevalece a perspectiva do modelo tradicional biomédico, que baseia-se "no princípio doença-cura e compreende de forma predominantemente orgânica o processo saúde-doença” (Yasui \& Costa-Rosa, 2008, p. 29). Fazendo um paralelo com o Movimento de Ouvidores de Vozes, pode-se dizer que o mesmo, ao entender as vozes como uma experiência e não como uma doença, acaba com a ideia de cura, e propõe, ao contrário, que o objetivo é auxiliar os ouvidores a conviver com as vozes, e não extingui-las (Baker, 2016; Romme \& Escher, 2000).

A partir do exposto, se reforça o fato de que as vozes podem ser compreendidas, não apenas como uma experiência psicológica individual isolada, mas como um fenômeno que reflete as relações de poder do individuo com seu meio e vice-versa. Portanto, além de ser um fenômeno psicológico, as vozes são também um fenômeno social (Romme \& Escher, 1997). As falas a seguir ilustram essa temática:

Com as vozes... Olha eu tento levar na esportiva sabe? Conversar com eles e ver o que é aproveitável e o que não é. É o que eu posso fazer. Eles estão ali, tão junto comigo. Os remédios ajudam até um certo ponto né, então tem que ir levando. (Entrevistado 10) 
Eu consigo [argumentar com a voz], só que assim... eu... não é da mesma forma, as coisas não acontecem da mesma forma que a gente ta conversando, eu tô conversando aqui, eu tô te olhando. Essas coisas acontecem a nível de pensamento, eu sempre respondo quando esse meu obsessor... quando eu tô nos meus momentos de crise e ele tá praticamente dominando meu cérebro, e ele diz pra mim "não, tu tem que terminar com a tua vida” às vezes eu chego a pegar uma caixa de remédio e digo pra ele "não, eu não vou fazer isso, não vou fazer isso porque se eu te prejudiquei em uma outra vida e te levei ao suicídio, eu já me arrependi, eu já não sou mais aquela pessoa, eu quero fazer diferente, eu quero ser diferente", eu respondo pra ele. (Entrevistada 11)

Nas falas apresentadas, ficam evidentes as influências dos meios sociais de cada um, tanto no que se refere ao sentido que a medicação possui no cotidiano do entrevistado 10, quanto no papel da religiosidade, para a entrevistada 11, que a utiliza como forma de dar sentido às vozes e dialogar com as mesmas. Em ambos os casos, os ouvidores utilizam o diálogo com as vozes como estratégia para conviver com elas.

Uma das técnicas propostas por Romme e Escher (2000) é “adiar ordens”. De acordo com os autores, quando os ouvidores sentem-se muito pressionados a fazer o que as vozes mandam, como no caso da entrevistada 11, é interessante que eles experimentem não fazer o que as vozes dizem, nem entrar em discussão com as mesmas, e apenas esperar, até mesmo cronometrando, quanto tempo leva para as ordens cessarem. O objetivo desta técnica é aprender a esperar e ver o que acontece quando o ouvidor não faz nada a respeito do que as vozes mandam, além de mostrar que, no final, são as vozes que acabam cedendo (Romme \& Escher, 2000).

No estudo de Petrus et al. (2012), além da estratégia de "manipular e regular as vozes", encontrou-se que "mudar a percepção e o significado atribuído às vozes" também foi muito utilizado pelos participantes do estudo. Segundo os autores, essa mudança possibilitou desenvolver um equilíbrio entre os sujeitos e as vozes, os quais passaram a considerá-las como parte de si mesmos e de suas vidas, fazendo-os sentir maior controle sobre elas (Petrus, et al., 2012).

Outro estudo que apresenta ideia semelhante é o desenvolvido pelas autoras da presente pesquisa (Couto \& Kantorski (2018). As mesmas desenvolveram uma revisão sistematizada da bibliografia sobre a temática da audição de vozes em duas bases de dados - PubMed e Lilacs -, nas quais obtiveram um total de 2.464 títulos de artigos para serem examinados. Destes, 35 preencheram os critérios de inclusão do estudo, e mostraram que o sentido que o ouvir atribui às vozes, a relação que ele estabelece com as mesmas e as estratégias que utiliza, são fatores que estão diretamente relacionados entre si. Evidenciando, portanto, que para o desenvolvimento de estratégias efetivas para lidar com a experiência, é preciso que o ouvidor a ressignifique, ou seja, elabore sentidos para essas vozes que o permitam conviver com as mesmas em uma relação positiva, do contrário, as estratégias utilizadas tendem a ser mais desadaptativas (Couto \&Kantorski (2018).

A partir do exposto, é possível observar que, dos 16 sujeitos entrevistados, 6 possuíam estratégias bastante desadaptativas para lidar com as vozes, 8 já haviam desenvolvido estratégias mais saudáveis para lidar com elas, e apenas 2 não souberam relatar de que forma lidavam com a experiência. Metade dos participantes do estudo ter apresentado estratégias desadaptativas para lidar com as vozes é condizente com o fato de serem todos usuários de serviço de saúde mental, visto que a procura pelo serviço se dá, justamente, pela dificuldade em lidar com a experiência. 
É possível também, que a participação no grupo de ouvidores de vozes venha contribuindo para a mudança desse cenário, visto que metade dos entrevistados já apresentou formas mais profícuas e estáveis de lidar com as vozes. Percebe-se ainda, que a resistência ao modelo biomédico através do desenvolvimento de estratégias para lidar com as vozes pode se dar de diferentes formas, sendo a mais almejada delas a diminuição do uso da medicação através do estabelecimento de uma boa relação com as vozes e um manejo adequado da experiência. No quadro 2, é possível visualizar as principais estratégias utilizadas por cada um dos ouvidores para lidar com as vozes.

\section{Quadro 2 - estratégias utilizadas pelos entrevistados}

\begin{tabular}{|c|c|}
\hline Entrevistado & Estratégias utilizadas \\
\hline 1 & Questionar o que as vozes dizem \\
\hline 2 & Suicídio \\
\hline 3 & Jogar vídeo game \\
\hline 4 & Ignorar as vozes \\
\hline 5 & Ignorar as vozes \\
\hline 6 & Conversar sobre as vozes \\
\hline 7 & Conversar com as vozes e ignorar as vozes \\
\hline 8 & Não soube explicar \\
\hline 9 & Crocura estabelecer um diálogo com as vozes \\
\hline 10 & Conversar com as vozes \\
\hline 11 & Ouvir rádio \\
\hline 12 & Não soube explicar \\
\hline 13 & Averiguar se as vozes são reais \\
\hline 14 & Conversar com as vozes \\
\hline 15 & Suicídio \\
\hline 16 & \\
\hline
\end{tabular}

Fonte: dados do trabalho de campo da pesquisa, 2018.

\section{Considerações finais}

O presente estudo objetivou compreender a experiência de ouvir vozes a partir das características e conteúdos das vozes, e das estratégias utilizadas por ouvidores usuários de serviço de saúde mental. No que se refere às características das vozes, evidenciou-se que estas podem ser determinantes das reações emocionais dos ouvidores frente à experiência. Dessa forma, vozes de comando possuem uma tendência de trazer maior prejuízo ao cotidiano dos indivíduos.

O fato de a maioria dos entrevistados terem apresentado vozes com características negativas vai ao encontro de dados de pesquisas populacionais, que constataram que os usuários de serviço de saúde mental ouvem mais vozes negativas do que os não usuários. Da mesma forma, as entrevistas mostraram que a audição de vozes não abrange apenas a audição, mas todos os outros sentidos, e que tem início, na maioria das vezes, com eventos traumáticos ou estressantes. 
Além disso, os entrevistados mostraram que, independentemente das dificuldades enfrentadas para lidar com as vozes, os focos de resistência ao modelo biomédico estão por toda parte, até mesmo dentro de um serviço que ainda funciona de acordo com esse modelo. Isso evidencia os desafios que a compreensão do Movimento de Ouvidores de Vozes acerca dessa experiência ainda encontra nas práticas cotidianas do trabalho em saúde mental, mesmo nos CAPS, que são serviços provenientes da reforma psiquiátrica e que deveriam trabalhar na contramão do modelo biomédico, com foco na saúde, priorizando a autonomia dos sujeitos, a reinserção social efetiva e um conceito de cuidado mais amplo, para além do uso da medicação.

Há também os desafios culturais, pois assim como o tratamento medicamentoso ainda é prevalente no tratamento das pessoas que ouvem vozes, a ideia de que essa experiência se constitui em uma doença também o é na sociedade brasileira. Contudo, já é possível evidenciar uma bibliografia crescente no país acerca da temática, que até pouco tempo era bastante escassa, além de um número também crescente de grupos de ouvidores de vozes, mostrando que essa nova abordagem está se expandindo.

Finalmente, o estudo aponta para a necessidade de uma construção acadêmica crítica acerca da experiência de ouvir vozes na formação dos profissionais da área da saúde, que apresente essa nova abordagem do tema, não vinculada ao modelo biomédico. É importante também, que os serviços respeitem o tipo de recuperação de cada ouvidor, atuando de forma mais compreensiva e produtora de significado, pois práticas responsáveis podem ser elaboradas em conjunto, quando pessoas são atendidas igualmente, como seres humanos também responsáveis pelo processo de mudança.

\section{Referências}

Andrew, E. M., Gray, N. S., \& Snowden, R. J. (2008). The relationship between trauma and beliefs about hearing voices: a study of psychiatric and non-psychiatric voice hearers. Psychological medicine, 38(10), 1409-1417.

Armstrong, N. \& Murphy, E. (2015). Conceptualizing resistance. Health, 16(3), 314-326.

Baker, P. (2016). Abordagem de Ouvir Vozes: Treinamento Brasil. CENAT - Centro Educacional Novas Abordagens Terapêuticas. Recuperado de https://materiais.cenatcursos.com.br/guiapessoas-ouvem-vozes

Bardin, L. (2011). Análise de conteúdo. São Paulo: Edições 70.

Beavan, V. \& Read, J. (2010). Hearing voices and listening to what they say: The importance of voice content in understanding and working with distressing voices. The Journal of nervous and mental disease, 198(3), 201-205.

Connor, C. \& Birchwood, M. (2013). Power and perceived expressed emotion of voices: their impact on depression and suicidal thinking in those who hear voices. Clinical psychology \& ${ }^{2}$ sychotherapy, 20(3), 199-205.

Contini, C. (2017). Ouvir vozes: Manual de enfrentamento. Pelotas/RS: Cópias Santa Cruz.

Corstens, D., Longden, E., Mccarty-Jones, S., Waddingham, R., \& Thomas, N. (2014). Emerging perspectives from the Hearing Voices Movement: implications for research and practice. Schizophrenia bulletin, 40(Suppl. 4), S285-S294. 
Couto, M. L.O. \& Kantorski, L. P. (2018). Ouvidores de vozes. Psicologia USP, 29(3), 418-431.

Curson, D. A., Barnes, T. R., Bamber, R. W., Platt, S. D., Hirsch, S. R., \& Duffy, J. C. (1985). Long-term depot maintenance of chronic schizophrenic out-patients: The seven year followup of the Medical Research Council fluphenazine/placebo trial. The British Journal of Psychiatry, $146(5), 464-480$.

De Jager, A., Rhodes, P., Beavan, V., Holmes, D., McCabe, K., Thomas, N., McCarthy-Jones, S. et al. (2016). Investigating the lived experience of recovery in people who hear voices. Qualitative health research, 26(10), 1409-1423.

Eaton, W., Romanoski, A., Anthony, J., \& Nestadt, G. (1991). Screening for psychosis in the general population with a self-report interview. The Journal of Nervous and Mental Disease, 179(11), 689-693.

Ellett, L., Luzon, O., Birchwood, M., Abbas, Z., Harris, A., \& Chadwick, P. (2017). Distress, omnipotence, and responsibility beliefs in command hallucinations. British Journal of Clinical Psychology, 56(3), 303-309.

Faccio, E., Romaioli, D., Dagani, J., \& Cipolletta, S. Auditory hallucinations as a personal experience: analysis of non-psychiatric voice hearer's narrations. Journal of psychiatric and mental health nursing, 20(9), 761-767.

Foucault, M. (2001). Dits et écrits II. (1976-1988). Paris: Gallimard.

Grabois, P. F. (2011). Resistência e revolução no pensamento de Michel Foucault: contracondutas, sublevações e lutas. Cadernos de Ética e Filosofia Política, 19, 7-27.

Henning, P. C. (2008). Efeitos de sentido em discursos educacionais contemporâneos: produção de saber e moral nas ciências humanas. Tese de Doutorado, Programa de Pós-graduação em Educação, Universidade do Vale do Rio dos Sinos - UNISINOS - São Leopoldo, RS. Recuperado de http://www.repositorio.jesuita.org.br/bitstream/handle/UNISINOS/2079/paula\%20correa.pdf? sequence $=1 \&$ isAllowed $=\mathrm{y}$

Johns, L.C. \& van Os, J. (2001) The continuity of psychotic experiences in the general population. Clinical Psychology Review, 21(8), 1125-1141.

Kantorski, L. P., Antonacci, M. H., Andrade, A. P. M., Cardano, M., \& Minelli, M. (2017). Grupos de ouvidores de vozes: estratégias e enfrentamentos. Saúde Debate, 41(115), 1143-1155.

Lei n. 10.216, de 06 de abril de 2001. (2001). Dispõe sobre a proteção e os direitos das pessoas portadoras de transtornos mentais e redireciona o modelo assistencial em saúde mental. Recuperado de http://www.planalto.gov.br/ccivil 03/leis/leis 2001/110216.htm

León-Palacios, M., Úbeda-Gómez, J., Escudero-Pérez, S., Barros-Albarán, M. D., López-Jiménez, A. M., \& Perona-Garcelán, S. (2015). Auditory verbal hallucinations: can beliefs about voices mediate the relationship patients establish with them and negative affect? The Spanish journal of psychology, 18, 1-8.

Mackinnon, A., Copolov, D. L., \& Trauer, T. (2004). Factors associated with compliance and resistance to command hallucinations. The Journal of nervous and mental disease, v. 192(5), 357-362.

Pires, R. R., Ximenes, V. M., \& Nepomuceno, B. B. (2013). Práticas de cuidado em saúde mental no Brasil: análise a partir do conceito de cidadania. Avances en Psicología Latinoamericana, 31(3), 507-521. Recuperado de http://www.scielo.org.co/scielo.php?pid=S1794$47242013000300005 \&$ script $=$ sci abstract\&tlng $=p t$ 
Petrus, Ng., Chun, R. W. K., \& Tsun, A. (2012). Recovering from hallucinations: A qualitative study of coping with voices hearing of people with schizophrenia in Hong Kong. The Scientific World Journal, 2012, 1-8.

Place, C., Foxcroft, R., \& Shaw, J. (2011). Telling stories and hearing voices: Narrative work with voice hearers in acute care. Journal of psychiatric and mental health nursing, 18(9), 837-842.

Resolução n. 466, de 12 de dezembro de 2012.(2012). Diretrizes e normas regulamentadoras de pesquisa envolvendo seres humanos. Recuperado de https://bvsms.saude.gov.br/bvs/sau-

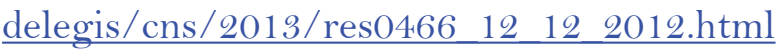

Romme, M., \& Escher, S. (1997). Na companhia das vozes - para uma análise da experiência de ouvir vozes. Lisboa: Estampa.

Romme, M. \& Escher, S. (2000). Making Sense of Voices: A guide for mental health professionals working with voice-hearers. London: MIND Publications.

Sharma, R. P., Dowd, S. M., \& Janicak, P. G. (1999). Hallucinations in the acute schizophrenictype psychosis: Effects of gender and age of illness onset. Schizophrenia Research, 37(1), 91-95.

Shevlin, M., Murphy, J., Dorahy, M. J., \& Adamson, G. (2007). The distribution of positive psychosis-like symptoms in the population: a latent class analysis of the National Comorbidity Survey. Schizophrenia research, 89(1), 101-109.

Sidgwick, H. (1894). Report on the census of hallucinations. In Proceedings of the society for psychical research (pp. 25-394). Londres: Trübner \& Co.

Silva, G. C. C. D., Santos, L. M., Teixeira, L. A., Lustosa, M. A., Couto, S. C. R., Vicente, T. A., \& Pagotto, V. P. F. (2005). A mulher e sua posição na sociedade: da antiguidade aos dias atuais. Revista da SBPH, 8(2), 65-76.

Sommer, I. E., Daalman, K., Rietkerk, T., Diederen, K. M., Bakker, S., Wijkstra, J., \& Boks, M. P. (2010). Healthy individuals with auditory verbal hallucinations; Who are they? Psychiatric assessments of a selected sample of 103 subjects. Schizophrenia Bulletin, 36(3), 633-641. doi:10.1093/schbul/sbn 130

Tien, A.Y. (1991). Distribution of hallucinations in the population. Social Psychiatry and Psychiatric Epidemiology, 26(6), 287-292.

Varese, F., Morrison, A. P., Beck, R., Heffernan, S., Law, H., \& Bentall, R. P. (2016). Experiential avoidance and appraisals of voices as predictors of voice-related distress. British Journal of Clinical Psychology, 55(3), 320-331.

Vaughan, S. \& Fowler, D. (2004). The distress experienced by voice hearers is associated with the perceived relationship between the voice hearer and the voice. British Journal of Clinical Psychology, 43(2), 143-153.

Yasui, S. \& Costa-Rosa, A. (2008). A Estratégia Atenção Psicossocial: desafio na prática dos novos dispositivos de Saúde Mental. Saúde em debate, 32(78/79/80), 27-37. 


\section{MARIA LAURA DE OLIVEIRA COUTO \\ http://orcid.org/0000-0002-5103-3000}

É psicóloga, mestre em Ciências pelo Programa de Pós-graduação

em Enfermagem da Universidade Federal de Pelotas, RS.

Endereço: Rua General Osório nº 858 ap 301, Pelotas/RS. Cep: 96020000.

E-mail: lauracouto@,uol.com.br

\section{LUCIANE PRADO KANTORSKI}

http://orcid.org/0000-0001-9726-3162

É enfermeira, doutora em Enfermagem. Docente titular da Faculdade de Enfermagem da Universidade Federal de Pelotas, RS.

E-mail: kantorski@,uol.com.br

\begin{tabular}{|c|c|}
\hline Histórico & $\begin{array}{l}\text { Submissão: 11/02/2019 } \\
\text { Revisão: 09/12/2019 } \\
\text { Aceite: 20/02/2020 }\end{array}$ \\
\hline $\begin{array}{l}\text { Contribuição } \\
\text { dos autores }\end{array}$ & $\begin{array}{l}\text { Concepção: M.L.O.C., L.P.K. } \\
\text { Coleta de dados: M.L.O.C. } \\
\text { Análise de dados: M.L.O.C. } \\
\text { Elaboração do manuscrito: M.L.O.C., L.P.K. } \\
\text { Revisão crítica de conteúdo intelectual importante: L.P.K. } \\
\text { Aprovação final do manuscrito: L.P.K. }\end{array}$ \\
\hline $\begin{array}{l}\text { Consentimento } \\
\text { de uso de imagem }\end{array}$ & Não se aplica. \\
\hline $\begin{array}{l}\text { Aprovação, ética } \\
\text { e consentimento }\end{array}$ & $\begin{array}{l}\text { O estudo foi aprovado pelo Comitê de Ética da Faculdade de } \\
\text { Enfermagem da Universidade Federal de Pelotas sob parecer } \\
\text { de } \mathrm{n}^{\circ} 2.201 .138 \text {. }\end{array}$ \\
\hline Financiamento & O autor possui bolsa de doutorado da CAPES. \\
\hline
\end{tabular}

